\title{
Fratura exposta do colo do fêmur em adulto: Relato de caso e solução cirúrgica
}

\section{Open Fracture of the Femoral Neck in an Adult: Case Report and Surgical Solution}

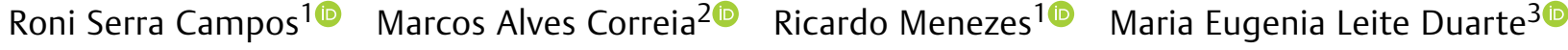 \\ João Antonio Matheus Guimarães 4 ()
}

${ }^{1}$ Serviço de Ortopedia, Hospital Estadual Alberto Torres (HEAT-RJ), Rio de Janeiro, RJ, Brasil

${ }^{2}$ Centro de Trauma Ortopédico, Instituto Nacional de Traumatologia e Ortopedia (INTO-RJ), Rio de Janeiro, RJ, Brasil

3 Divisão de Pesquisa, Instituto Nacional de Traumatologia e Ortopedia (INTO-RJ), Rio de Janeiro, RJ, Brasil

${ }^{4}$ Instituto Nacional de Traumatologia e Ortopedia (INTO-RJ), Rio de Janeiro, RJ, Brasil

Rev Bras Ortop

Endereço para correspondência João Antonio Matheus Guimarães, PhD, Instituto Nacional de Traumatologia e Ortopedia, Rio de Janeiro, RJ, Brasil (e-mail: jguimaraes@into.saude.gov.br; jmatheusguimaraes@gmail.com).

\section{Resumo \\ Palavras-chave \\ - fraturas expostas \\ - colo do fêmur \\ - adulto \\ - idoso}

\section{Abstract}

A fratura intracapsular do fêmur proximal é uma lesão frequente no paciente idoso, e em geral está associada a trauma de baixa energia e redução da massa óssea. No jovem, esta lesão é pouco frequente, decorre de trauma de alta energia, e resulta em dano das partes moles adjacentes. Contudo, o relato de fratura intracapsular do fêmur proximal com exposição óssea por trauma indireto é raro na literatura ortopédica. Neste relato, esta lesão foi diagnosticada em um homem de 35 anos, vítima de acidente automobilístico. Mediante um mecanismo semelhante ao da luxação posterior do quadril, o segmento proximal do fêmur determinou exposição óssea através da região glútea. Foram descritos o tratamento inicial e os tratamentos subsequentes até a solução definitiva por artroplastia total do quadril associada a transposição muscular para reconstrução do mecanismo abdutor do quadril. Após 10 meses de seguimento, o paciente apresentava boa recuperação funcional, com retorno gradual da força abdutora, Harris Hip Score de 91 pontos, com estudo radiográfico revelando prótese total cimentada bem posicionada. A estratégia terapêutica utilizada neste paciente (artroplastia total do quadril com transferência muscular para a reconstrução da musculatura abdutora) foi uma solução eficiente para tratar a fratura intracapsular do fêmur proximal com exposição óssea.

Intracapsular proximal femoral fracture is a frequent injury in elderly patients, often associated with low-energy trauma and reduced bone mass. In young patient, it is recebido

08 de Maio de 2020

aceito

16 de Setembro de 2020
DOI https://doi.org/

$10.1055 / \mathrm{s}-0040-1721842$. ISSN 0102-3616. (c) 2021. Sociedade Brasileira de Ortopedia e Traumatologia. All rights reserved.

This is an open access article published by Thieme under the terms of the Creative Commons Attribution-NonDerivative-NonCommercial-License, permitting copying and reproduction so long as the original work is given appropriate credit. Contents may not be used for commercial purposes, or adapted, remixed, transformed or built upon. (https://creativecommons.org/ licenses/by-nc-nd/4.0/)

Thieme Revinter Publicações Ltda., Rua do Matoso 170, Rio de Janeiro, RJ, CEP 20270-135, Brazil 


\author{
Keywords \\ - fractures, open \\ - femur neck \\ - adult \\ - aged
}

uncommon, usually caused by high-energy trauma and accompanied by damage to the adjacent soft tissues. However, reports of open intracapsular proximal femoral fracture due to indirect trauma are rare in the orthopedic literature. In the present article, we describe a case of this injury in a 35-year-old man involved in a car accident. The proximal femur was exposed at the gluteal region due to a mechanism similar to dislocation of the posterior hip. We describe the initial treatment and subsequent management until achieving a definitive solution using total hip arthroplasty and muscle transfer to reconstruct the abductor mechanism of the hip. At 10 months of follow-up, the patient presented good functional outcome, with gradual recovery of the abductive strength and a Harris Hip Score of 91 points. In addition, a radiographic study showed that the cemented total prosthesis was well-positioned. This therapeutic strategy (total hip arthroplasty with muscle transfer to reconstruct the abductor musculature) was successful to treat an intracapsular proximal femoral fracture with bone exposure.

\section{Introdução}

A fratura do colo do fêmur em pacientes com menos de 50 anos representa menos de $5 \%$ de todas as fraturas do quadril, e decorre de trauma de alta energia, com consequente dano às partes moles. ${ }^{1} \mathrm{O}$ padrão da fratura, a cominuição no foco de fratura, e o grau de desvio dos fragmentos estão associados às complicações do tratamento cirúrgico, tais como falta de consolidação, falha da osteossíntese, e necrose avascular da cabeça do fêmur. ${ }^{2}$ Quando esta fratura está associada a um trauma de tamanha magnitude que acarrete exposição óssea e lesão extensa de partes moles na região do quadril, o problema se torna único e de difícil solução terapêutica.

\section{Relato do caso}

Paciente do sexo masculino, de etnia branca, 35 anos de idade, solteiro, sofreu acidente automobilístico, com típica lesão por trauma no painel do carro, que determinou fratura cominutiva do colo do fêmur esquerdo, com migração proximal do segmento diafisário e extensa lesão de partes moles através da musculatura glútea, com exposição óssea. Na avaliação clinica durante o atendimento inicial, o paciente estava lúcido, eupneico, sem queixas torácicas ou abdominais, e sem sinais de instabilidade hemodinâmica. No exame físico, ele relatava dor intensa na região do quadril, com sangramento em ferida na região glútea esquerda. 0 exame clínico também revelou dor e impotência funcional no joelho ipsolateral, sugerindo possível lesão do ligamento cruzado posterior devido à presença de instabilidade articular. O estudo radiográfico convencional revelou fratura cominutiva e desviada do colo femoral esquerdo. A inspeção da ferida evidenciou a presença de fragmentos ósseos, confirmando se tratar de fratura exposta do colo femoral ( - Figura 1). No centro cirúrgico, foi feita a limpeza mecanocirúrgica da fratura, com lavagem exaustiva da ferida. A fratura foi alinhada por tração, e a ferida foi fechada por planos. Foi iniciada antibioticoterapia com cefazolina venosa e profilaxia tetânica. Cinco dias após o trauma inicial, foi realizado um novo procedimento cirúrgico pelo acesso anterolateral para avaliar a possibilidade de uma redução direta e osteossíntese. 0 achado cirúrgico foi devastador, traduzido por uma grave lesão com desvascularização do segmento cefálico do fêmur, associado à completa desinserção dos músculos psoas ilíaco, glúteo menor, glúteo médio, e rotadores externos. Existia ainda lesão capsulolabral circunferencial da articulação do quadril. Optou-se pela realização da ressecção do segmento cefálico com a colocação de um espaçador não articulado de cimento ósseo com antibiótico (vancomicina) para aguardar o planejamento subsequente de uma artroplastia total do quadril (-Figura 2). Após oito semanas, com exames de

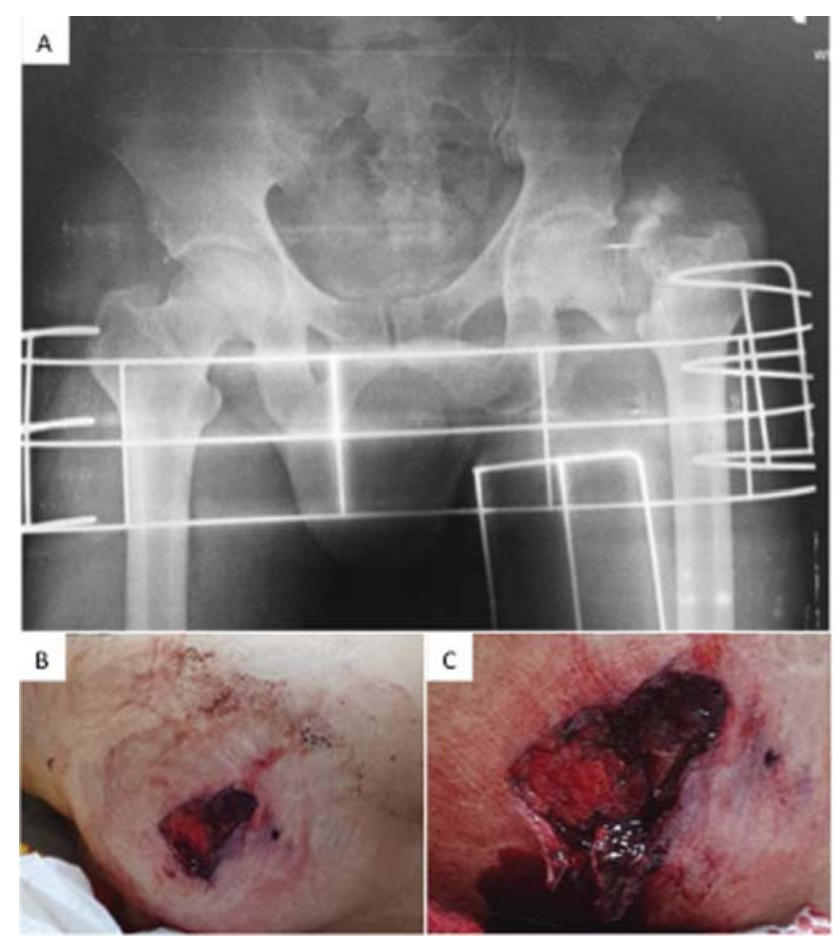

Fig. 1 Avaliação clínica e radiográfica no atendimento inicial do paciente: (A) radiografia em incidência anteroposterior (AP) panorâmica da bacia mostrando fratura cominutiva do colo femoral esquerdo com importante migração cefálica; (B) ferida na região glútea esquerda; (C) lesão muscular extensa com sangramento e esquírolas ósseas confirmando o diagnóstico de fratura exposta do colo femoral. 


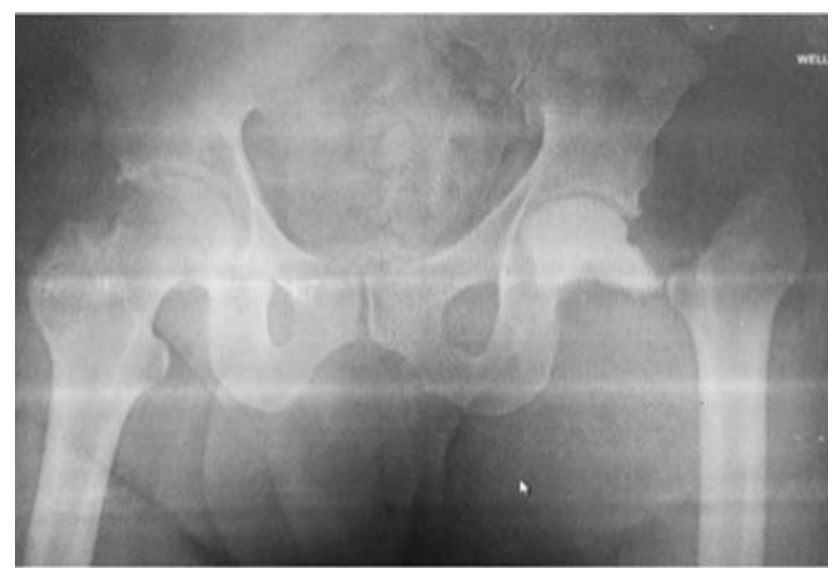

Fig. 2 Radiografia em incidência AP panorâmica da bacia realizada após o procedimento de ressecção da cabeça femoral e colocação do espaçador não articulado.

cultura negativos, níveis normais de velocidade de sedimentação das hemácias (VHS) e proteína C reativa (PCR), foi realizado o terceiro procedimento. Mediante um acesso posterolateral, após a retirada do espaçador, foi realizada artroplastia total cimentada do quadril. Em seguida, foi realizada a transferência do músculo glúteo máximo para restaurar o mecanismo abdutor do quadril, seguindo a técnica descrita por Whiteside ${ }^{3}$ em 2012 (-Figura 3). A técnica baseia-se na utilização de dois retalhos do músculo glúteo máximo: o inferior é suturado na cápsula anterior e na borda anterior do trocanter maior, para realizar a função do glúteo menor. $O$ retalho superior cruzou este primeiro retalho e foi fixado na região lateral do trocanter maior para realizar a função do glúteo médio (-Figura 4). O paciente evoluiu sem intercorrências, e recebeu alta hospitalar. Foi permitida carga parcial com apoio por três meses e realização de fisioterapia para recuperação funcional. 0 paciente evoluiu bem, com retorno gradual da força abdutora e negativação do sinal de Trendelenburg, sendo que, aos 10 meses de pós-operatório, apresentava um Harris Hip Score de 91 pontos, e a radiografia convencional revelava uma prótese total cimentada bem posicionada (-Figura 5).

\section{Discussão}

Em pesquisa realizada nos principais bancos de dados disponíveis (Medline Pubmed, Lilacs, Scielo, Cochrane Library), não encontramos relatos de lesão similar. Existem descrições de alguns casos de luxação exposta anterior do quadril em pacientes adultos, ${ }^{4-6}$ e a descrição de apenas um caso de luxação posterior exposta em adulto, resultante de atropelamento em via pública. ${ }^{7}$ No presente relato, o mecanismo do trauma foi o impacto do joelho sobre o painel do automóvel, que, geralmente, determina apenas luxação ou fratura-luxação posterior do quadril, através da parede posterior do acetábulo, que é mais vulnerável. Acreditamos que, no momento do trauma, o quadril do paciente provavelmente estava abduzido, com a cabeça femoral totalmente contida pelo teto acetabular. Assim, o vetor da força de cisalhamento acarretou a fratura do colo e a persistência da energia do impacto determinou a migração superior do segmento proximal do fêmur, a lesão extensa de partes moles, e a exposição óssea através da musculatura glútea. Este mecanismo é o mesmo que acarreta a fratura da cabeça do fêmur, geralmente associada a luxação posterior do quadril. ${ }^{8} \mathrm{~A}$ associação da lesão ligamentar do joelho ipsolateral também
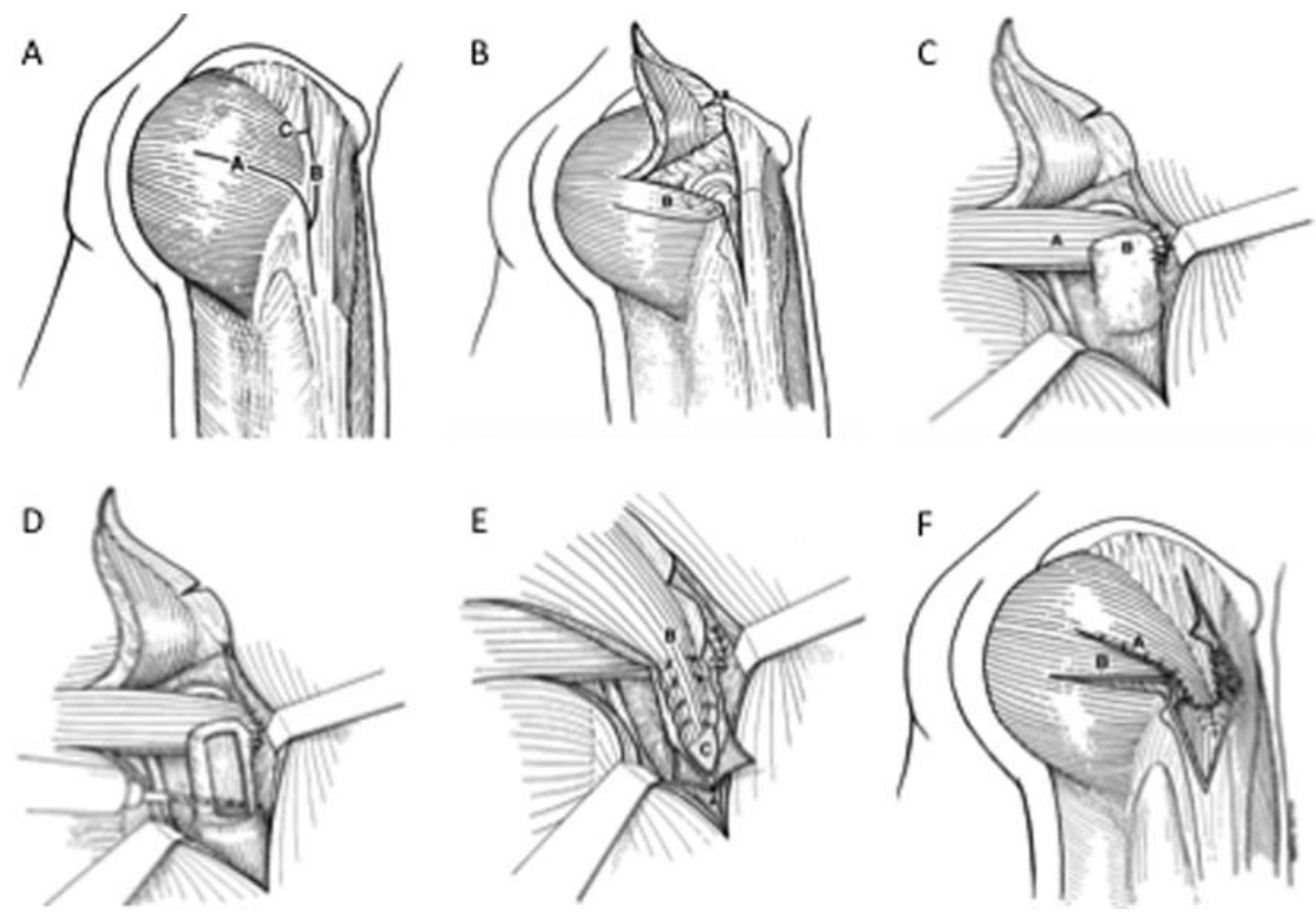

Fig. 3 Esquema da técnica da tranferência do glúteo máximo para restaurar o mecanismo abdutor do quadril: (A) planejamento dos retalhos do músculo glúteo máximo; (B) levantamento do retalho superior; (C) fixação do retalho inferior na parte anterior do colo femoral; (D) preparo do trocanter para receber o retalho superior; (E) fixação do retalho superior; (F) aspecto final da transferencia muscular, adaptado de Whiteside. ${ }^{3}$ 


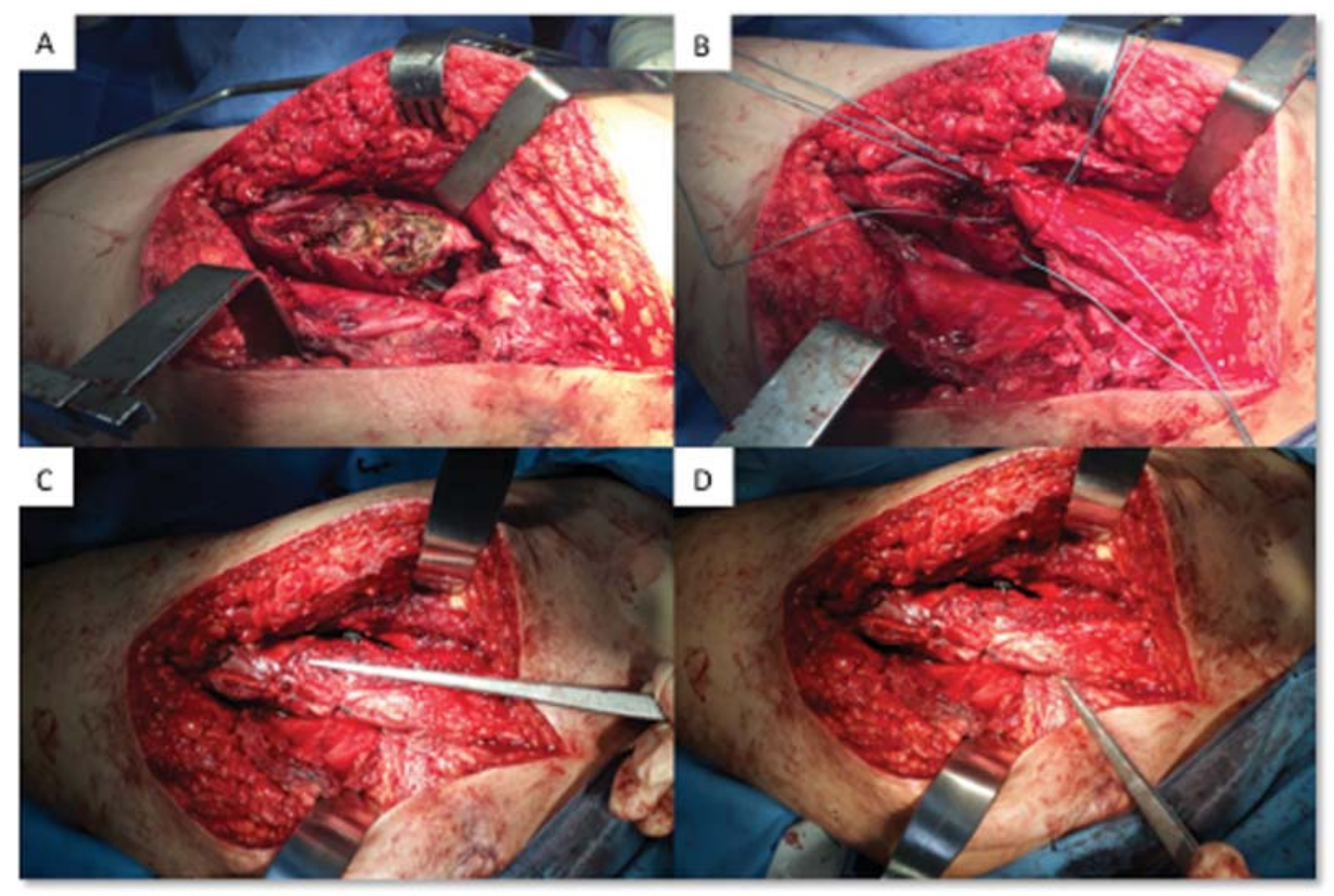

Fig. 4 Imagem cirúrgica da transferência do músculo glúteo máximo para restaurar o mecanismo abdutor do quadril: (A) preparo femoral; (B) confecção de dois retalhos com fibras preservadas do músculo glúteo máximo; (C) retalho superior cruzando o primeiro retalho e fixado na região lateral do trocanter maior para realizar a função do glúteo médio; (D) retalho inferior transferido para a parte superior do colo do fêmur, sob a ponta do trocanter maior, e suturado na cápsula anterior e na borda anterior do trocanter maior, para realizar a função do glúteo menor.

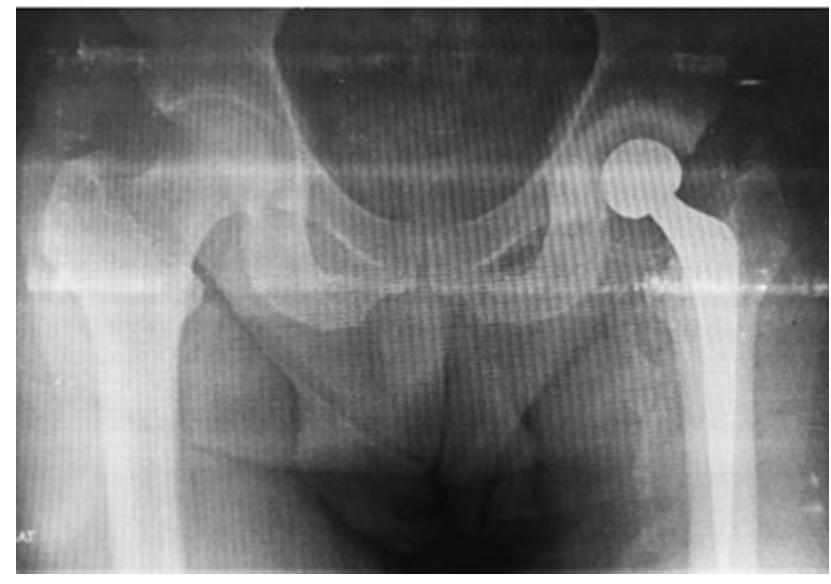

Fig. 5 Radiografia em incidência AP panorâmica da bacia realizada com dez meses de pós-operatório. Notar a presença de prótese total cimentada do quadril esquerdo bem posicionada.

é justificada por este mecanismo típico do trauma do joelho sobre o painel do automóvel no momento da colisão.

O suprimento sanguíneo da cabeça femoral é tênue e facilmente lesionado na fratura intracapsular desviada. A artéria circunflexa femoral medial nutre $82 \%$ da cabeça femoral e $67 \%$ do colo femoral. A artéria circunflexa femoral lateral contribui com $18 \%$ da vascularização para a cabeça femoral, e 33\% da do colo. Ambos os vasos se ramificam em delicadas artérias retinaculares que acompanham a superfície do colo do fêmur até atingir a cabeça femoral. ${ }^{9}$ No caso relatado, esse sistema encontrava-se lesado, associado a desinserção da musculatura trocantérica.
A opção terapêutica de realizar redução e osteossíntese foi descartada devido à cominuição do foco de fratura e pelo risco de necrose avascular da cabeça femoral. Dessa maneira, a indicação de artroplastia total do quadril foi determinada devido ao risco biológico de necrose asséptica da cabeça femoral e ao risco biomecânico, pois o índice de falha de uma osteossíntese na fratura com traço vertical e cominuição posterior do colo do fêmur é muito elevado. ${ }^{2}$ Outro aspecto importante foi a perda da musculatura abdutora do quadril, o que determina incapacidade importante na marcha, e pode predispor à luxação da prótese do quadril. 0 emprego da técnica descrita por Whiteside ${ }^{3}$ possibilitou a estabilização da prótese e minimizou o déficit clínico para a marcha. Considerando a evolução favorável do paciente, a transferência muscular descrita para casos de revisão de prótese de quadril quando há perda da musculatura abdutora ${ }^{10}$ foi eficaz no tratamento deste tipo de lesão. A artroplastia total do quadril associada à transferência muscular para a reconstrução da musculatura abdutora foi uma solução eficiente para tratar uma fratura exposta do colo do fêmur.

Conflito de Interesses

Os autores declaram não haver conflito de interesses.

\section{Referências}

1 Robinson CM, Court-Brown CM, McQueen MM, Christie J. Hip fractures in adults younger than 50 years of age. Epidemiology and results. Clin Orthop Relat Res 1995;(312):238-246

2 Liporace F, Gaines R, Collinge C, Haidukewych GJ. Results of internal fixation of Pauwels type-3 vertical femoral neck fractures. J Bone Joint Surg Am 2008;90(08):1654-1659 
3 Whiteside LA. Surgical technique: Transfer of the anterior portion of the gluteus maximus muscle for abductor deficiency of the hip. Clin Orthop Relat Res 2012;470(02):503-510

4 Grundy M, Kumar N. Open anterior dislocation of the hip. Injury 1982;13(04):315-316

5 Lamberti PM, Rabin SI. Open anterior-inferior hip dislocation. J Orthop Trauma 2003;17(01):65-66

6 Oliveira AL, Machado EG. Luxação anterior exposta do quadril em adulto: relato de caso e revisão da literatura. Rev Bras Ortop 2014; 49(01):94-99

7 Hamzaoglu A, Aydinok HC, Pinar H, Asik M, Cakmak M. Open traumatic posterior dislocation of the hip. A case report. Arch Orthop Trauma Surg 1992;111(06):345-347
8 Guimarães RP, Saeki de Souza G, da Silva Reginaldo S, et al. Study of the treatment of femoral head fractures. Rev Bras Ortop 2015; 45(04):355-361

9 Dewar DC, Lazaro LE, Klinger CE, et al. The relative contribution of the medial and lateral femoral circumflex arteries to the vascularity of the head and neck of the femur: a quantitative MRI-based assessment. Bone Joint J 2016;98-B(12): $1582-1588$

10 Jang SA, Cho YH, Byun YS, Gu TH. Abductor reconstruction with gluteus maximus transfer in primary abductor deficiency during total hip arthroplasty. Hip Pelvis 2016;28 (03):178-181 